\title{
A Method for Determining Sending Rates of Peers for Efficient Network Resource Utilization in P2P Environment
}

\author{
Park Jaesung ${ }^{+}$
}

\begin{abstract}
The performance of P2P application services may be improved by reducing unnecessary inter-network traffic through intelligent peer selection. However, since a logical link between peers in a P2P overlay network is composed of a set of physical links in an underlay network, the traffic pattern determined by the sending rates of selected peers imposes loads on each underlay links. Thus, if the sending rates are not determined carefully, the loads between underlay links may not be balanced, which means some links are underloaded while the other links are congested. In this paper, we take an optimization approach to determine the sending rates of peers strategically to avoid the inefficient use of underlay links. The proposed scheme also guarantee the minimum receiving rates of peers while minimizing the maximum link utilization of underlay links, which is beneficial both to P2P applications and an underlay network.
\end{abstract}

\section{Keywords : P2P Application Service, Maximum Link Utilization, Optimal Sending Rate}

\section{$\mathrm{P} 2 \mathrm{P}$ 환경에서 효율적 망 자원 이용을 위한 피어의 송신률 결정 방법}

\author{
박 재 성 ${ }^{+}$
}

요 약

$\mathrm{P} 2 \mathrm{P}$ 응용 서비스의 성능은 피어 선택의 지능화를 통해 불필요한 망간 트래픽 교환양을 줄임으로써 향상시킬 수 있다. 그러나 P2P 오버레이 망의 피어간 논리적 링크는 하부 망의 물리적 링크들로 구성되기 때문에 선택된 피어의 송신률에 의해 결정되는 트래픽 패턴에 따라 하부 링 크들에 부가되는 부하는 달라진다. 따라서 피어의 송신률이 신중하게 결정되지 않는다면 일부 하부 망 링크들의 이용률은 낮은 반면 다른 링크 들은 혼잡하게 되는 부하 불균형 문제가 발생된다. 이와 같은 하부 망 자원의 비효율적 이용 현상을 방지하기 위해 본 논문에서는 최적화 기법 을 통해 피어의 송신률을 결정하기 위한 전략적 방안을 제안한다. 제안 기법은 피어의 수신률을 일정 수준으로 보장함과 동시에 하부 망의 링 크 이용률의 최대값을 최소화 할 수 있도록 서버 피어의 송신률을 결정함으로써 하부 망 자원의 효율적 이용과 클라이언트 피어에게 일정 수 준의 서비스 품질을 제공한다.

키워드 : P2P 응용 서비스, 최대 링크 이용률, 최적 송신률

\section{1. 서 론}

단일 서버로부터 데이터를 수신받는 클라이언트/서버 구 조와 달리 P2P (Peer-To-Peer) 구조에서 클라이언트 피어 (peer)는 다수의 서버 피어들로부터 데이터를 수신할 수 있

\footnotetext{
※ 이 논문은 2012 년도 정부(교육과학기술부)의 재원으로 한국 연구재단의 기 초연구사업(No.2012-0002621)의 지원과 경기도의 경기도지원협력 연구센터 (GRRC) 사업[(GRRC 수원2012-B4) 실시간 상황 대응을 위한 정밀 위치추적 시스템연구]의 일환으로 수행하였음

† 정 회 원: 수원대학교 정보보호학과 조교수

논문접수: 2012년 6월 20일

수 정 일 : 1 차 2012년 7월 24일

심사완료: 2012년 8월 1일

* Corresponding Author:Park Jaesung(jaesungpark@suwon.ac.kr)
}

다. 데이터 송신자를 유연하게 선택할 수 있다는 특징으로 인해 $\mathrm{P} 2 \mathrm{P}$ 시스템은 확장성과 강건성 (robustness)이 뛰어나 다. 그러나 $\mathrm{P} 2 \mathrm{P}$ 시스템은 망 상태 정보와 무관하게 서버 피 어를 선정하므로 클라이언트 피어와 서버 피어의 임의 조합 으로 발생되는 예측 불가능한 트래픽 패턴은 트래픽 엔지니 어링을 통한 망의 트래픽 제어 기능의 효용성을 감소시키며 [1], 불필요한 망간 (inter network) 트래픽을 발생시켜 P2P 응용 서비스의 성능도 감소시킨다. 이와 같은 문제점을 해 결하기 위해 어플리케이션의 트래픽 최적화를 위한 연구들 과[2] 표준화가 진행 중이다[3]. 이들은 망 내에 $\mathrm{P} 2 \mathrm{P}$ 포털 (portal)을 두어 망과 피어의 상태 정보를 유지하며 클라이 언트 피어가 서버 피어를 선택할 때 이들 정보를 제공하여 
클라이언트 피어와 지리적으로 가까운 피어를 서버 피어로 선택하게 함으로써 피어들 사이에 불필요한 망간 트래픽 발 생을 억제하는 것을 목적으로 한다[4].

그러나 이와 같은 환경에서도 소스 피어가 각 클라이언트 피어에 전송하는 데이터 송신률에 따라 하부 망 자원의 이 용률은 달라지게 된다[5]. 즉, 소스 피어들의 송신률에 따라 일부 하부 망 링크의 이용률은 낮은 반면 타 하부 망 링크 는 혼잡하게 되는 문제가 발생될 수 있으므로 선택된 피어 의 송신률을 체계적으로 결정하기 위한 방안이 필요하다. 따라서 본 논문에서는 $\mathrm{P} 2 \mathrm{P}$ 포털 표준 구조를[3] 따르는 $\mathrm{P} 2 \mathrm{P}$ 환경에서 하부 망 링크들의 이용률 불균형을 완화하여 망 자원을 효율적으로 이용하기 위한 서버 피어의 송신률 결정 방법을 제안한다. 제안 기법은 $\mathrm{P} 2 \mathrm{P}$ 응용 서비스의 품질을 고려하여 클라이언트 피어의 최소 수신률을 보장하며 피어 들 간의 하부 망 경로 정보를 이용하여 하부 망 링크의 최 대 이용률을 최소화시킨다. 모의 실험을 통해 제안 기법은 클라이언트 피어가 서버 피어를 임의로 선택하는 방식이나 (RandomDist)[10] 클라이언트 피어가 제공 용량이 가장 큰 서버 피어들을 선택하는 방식에 (HighestFirst)[11] 비해 전 체 서버 피어가 발생시킨 부하를 하부 망 링크들에 보다 균 등하게 분산시켜 망 자원을 보다 효율적으로 사용한다는 것 을 정량적으로 검증하였다.

\section{2. 피어의 송신률 결정 방법}

본 논문에서는 메쉬 형태의 $\mathrm{P} 2 \mathrm{P}$ 오버레이 망을 가정하여 [6] 각 피어는 다수의 피어들로부터 데이터를 수신할 수 있 으며 다수의 피어들에게 수신한 데이터를 전송할 수 있다. 또한 본 논문에서는 $\mathrm{P} 2 \mathrm{P}$ 포털이 서버 피어의 송신률을 결 정하는 환경을 가정한다[7]. 이와 같은 환경에서는 $\mathrm{P} 2 \mathrm{P}$ 트래 픽의 지역화를 위한 서버 집합이 결정된 후 하부 망 자원의 효율적 이용을 위해 서버 피어들의 송신률을 결정하므로 분 산 제어 기법에 비해 성능이 우수하다. 임의의 클라이언트 피어 $a$ 와 서버 피어 $b$ 사이의 오버레이 링크는 하부 망의 물리적인 링크들로 구성된 물리적 경로에 해당된다. 트래픽 엔지니어링에 의한 하부 망 경로는 피어에 의한 $\mathrm{P} 2 \mathrm{P}$ 오버 레이 망 형상보다 느리게 변화하므로 피어 노드 사이의 하 부 망 경로는 고정되었다고 가정한다.

이와 같은 환경에서 하부 망의 물리 링크 $l$ 과 두 종단 피 어 $a, b$ 사이의 경로 $r$ 과의 관계를 나타내기 위해 다음과 같은 변수를 정의한다.

$$
\iota_{l, r}= \begin{cases}1 & r \text { 에 } l \text { 이 있는 경 우 } \\ 0 & \text { 그외의 경우 }\end{cases}
$$

$\mathrm{P} 2 \mathrm{P}$ 오버레이 망을 구성하는 서버 피어의 집합을 $V_{s}$, 클라이언트 피어의 집합을 $V_{c}$, 서버 피어 $b$ 가 클라이언트
피어 $a$ 로 전송하는 송신률을 $x_{a b}$ 로 표기하면 클라이언트 피어 $a$ 의 전체 수신률과 서버 피어 $b$ 의 전체 송신률은 다 음과 같이 얻을 수 있다.

$$
r_{a}=\sum_{b \in V_{s}} x_{a b}, \quad x_{b}=\sum_{a \in V_{c}} x_{a b}
$$

클라이언트 피어 $a$ 와 서버 피어 $b$ 의 쌍 $(a, b)$ 의 집합을 $S_{p}$ 로 표기하면 $s \in S_{p}$ 와 하부 망 경로 $r$ 과의 관계는 다음 과 같은 변수로 모델링된다.

$$
\kappa_{r, s}= \begin{cases}1 & s \in S_{p} \text { 가 } r \text { 을 사용하는 경 우 } \\ 0 & \text { 그외의 경우 }\end{cases}
$$

식 (1)과 식 (3)에 의해 하부 물리 링크 $l$ 에 부과되는 부 하는 다음과 같이 결정된다.

$$
y_{l}=\sum_{a \in V_{c}} \sum_{b \in V_{s}} \iota_{l, r} \kappa_{r, s} x_{a b}
$$

망 자원의 효율적 이용을 위해서는 $\mathrm{P} 2 \mathrm{P}$ 에 의해 하부 망에 부가되는 부하는 하부 망의 모든 링크에 균등하게 부과되어 야 한다. 이와 같은 특성을 나타내기 위한 성능 인자로 본 논문에서는 하부 망 링크의 최대 링크 이용률 (MLU: maximum link utilization)을 사용한다. 하부 링크 $l$ 의 최대 송신률을 $c_{l}^{m}$ 으로 표기하면 주어진 $x_{a b}$ 에 대해 하부 링크 $l$ 의 이용률은 식 (3)에 의해 $m_{l}=y_{l} / c_{l}^{m}$ 이 되므로 $x_{a b}$ 는 $\max \left(m_{l}\right)$ 을 최소화하도록 결정되어야 한다. 또한 $\mathrm{P} 2 \mathrm{P}$ 서 비스의 품질이 일정 수준 이상이 되기 위해 클라이언트 피어 의 수신률은 $r_{B}$ 이상이 되어야하며, 서버 피어 $b$ 의 송신률 은 자신의 최대 업로드 속도 $\left(U_{b}^{m}\right)$ 보다 작아야 한다. 더욱 이 하부 망 링크 $l$ 의 부하는 $c_{l}^{m}$ 을 넘어서는 안되므로 하부 망의 물리 링크들의 집합을 $L$ 로 표기하면 서버 피어의 송신 률 결정 문제는 다음과 같은 최적화 문제로 정의할 수 있다.

$$
P: \min \left\{\max \left(m_{l}\right)\right\}
$$

subject to

$$
\begin{aligned}
& y_{l} \leq c_{l}^{m}, \quad(l \in L) \\
& r_{a} \geq r_{B},\left(a \in V_{c}\right), \\
& 0 \leq x_{b} \leq U_{b}^{m}, \quad\left(b \in V_{s}\right)
\end{aligned}
$$

본 논문에서 $\mathrm{P} 2 \mathrm{P}$ 포털은 하부 망에서 제공하는 라우팅 정보와 $r_{B}, U_{b}^{m}$ 및 $S_{p}$ 를 이용하여 식 (5-1) (5-3)의 제 약조건들을 만족하며 식 (5)를 최소로 만드는 $x=\left(x_{11}, \ldots, x_{a b}, \ldots, x_{\mid V_{c} \| V_{s}}\right)$ 를 완결탐색을 통해 결정하였 


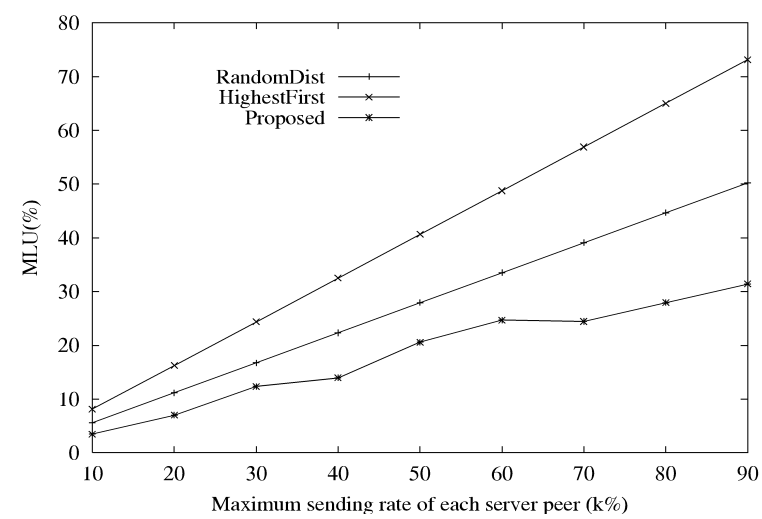

Fig. 1. Maximum link utilization for increaing loads of underlay network

다. 그러나 식 (5)의 최적화 문제는 부등식 제약 조건을 가 진 최적화 문제이므로 다양한 방법을 통해 완결탐색보다 빠 를 시간 안에 해를 구할 수 있다[9].

\section{3. 성능 평가}

본 절에서는 컴퓨터 모의 실험을 통해 제안 기법의 성능 을 RandomDist 방법[10] 및 HighestFirst 방법과[11] 정량적 으로 비교함으로써 제안기법의 타당성을 검증한다. 모의 실 험을 위해 클라이언트 피어가 4 개 $\left(n_{c}\right)$, 서버 피어가 3 개인 $\left(n_{s}\right)$ 환경을 설정하였으며 이들 사이의 메쉬 오버레이는 [8]에 따라 10 개의 하부 망 링크들의 임의 조합으로 구성하 였다. 각 물리 링크의 $c_{l}^{m}$ 은 $[0,1]$ 사이로 정규화하여 균등 (uniform) 분포에 따라 랜덤하게 설정하였다. 각 서버 피어 의 최대 송신률은 $[0, k] \quad(k<1)$ 사이에서 랜덤하게 설정 하였으며 하부 망의 부하에 따른 성능 비교 평가를 위해 $k$ 를 $10 \%$ 에서 $90 \%$ 로 변화시키면서 실험하였다. 또한 서버 송 신률의 총 합이 $r_{B}{ }^{*} n_{c}$ 보다 크고 대부분의 서버 피어의 송 신률을 클라이언트 피어가 사용하는 환경 구성을 위해 $r_{B}$ 는 서버 피어의 총 송신률의 합의 $90 \%$ 로 설정하였다.

위와 같은 환경에서 망의 총 부하양에 따른 최대 링크 이 용률을 Fig. 1에 도시하였다. 그림에서 보는 바와 같이 망에 부과되는 트래픽의 양이 증가할 수록 $\mathrm{MLU}$ 역시 증가한다. 그러나 제안 기법은 서버 피어의 송신률을 하부 망의 $\mathrm{MLU}$ 측면에서 최적화하여 결정하기 때문에 다른 두 기법들에 비 해 $\mathrm{MLU}$ 증가율은 현저히 낮다. 이와 같은 차이는 특히 하 부 망에 부과되는 부하가 증가할 수록 커지는 것을 볼 수 있다. 이와 같은 현상을 심도있게 분석하기 위해 Fig. 2에 $k=80 \%$ 이고 $r_{B}=0.1$ 인 경우 각 링크별 이용률을 도시 하였다. 하부 망 전체 이용율 측면에서 제안 기법은 $20.1 \%$, HighestFirst 기법은 20.7\%, RandomDist 기법은 23.3\%로 비슷하지만 Fig. 2에서 보는 바와 같이 다른 두 기법들은 링크별 이용률의 최대값과 최소값의 차이가 큰 반면 제안

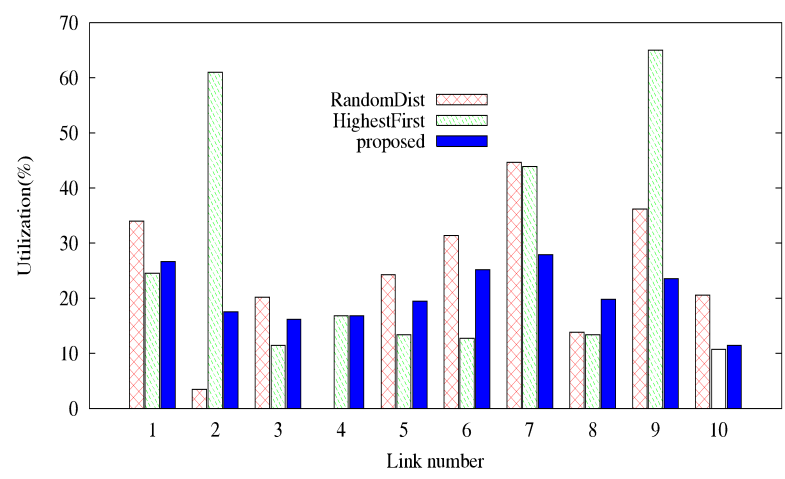

Fig. 2. Link utilization of each underlay links $(k=0.8)$

기법은 이들에 비해 그 차이가 작다는 것을 알 수 있다. 즉, 제안 기법은 피어들 사이의 경로와 하부 링크의 용량을 고 려하여 $\mathrm{P} 2 \mathrm{P}$ 트래픽을 분산시킴으로써 특정 링크의 이용률 이 낮은 상태에서 다른 링크가 과도하게 사용되는 자원 이 용률의 불균형을 방지한다.

\section{4. 결 론}

본 논문에서는 하부 망 자원의 효율적 이용을 위한 서버 피어의 송신률 결정 문제를 부등식 제약 조건을 가진 최적 화 문제로 모델링하였다. 또한 본 논문에서는 모의실험을 이용하여 제안기법은 하부 망 상태 정보를 이용한 최적화를 통해 타 기법에 비해 하부 망 링크의 MLU를 최소화하여 하부 망 자원 이용률의 불균형을 완화함으로써 망 자원을 보다 효율적으로 사용한다는 것을 검증하였다.

\section{참 고 문 헌}

[1] L.Qiu, Y.R. Yang, Y. Zhang, and S. Shenker, "On Selfish Routing in Internet-like Environments," ACM SIGCOMM, pp.151-162, Aug., 2003.

[2] V.K. Gurbani, V. Hilt, I. Rimac, M. Tomsu, and E. Marocco, "A Survey of Research on the Application-Layer Traffic Optimization Problem and the Need for Layer Cooperation," IEEE Communications Magazine, Vol.47, No.8, pp.107-112, Aug., 2009,

[3] J. Seedorf, and E. Burger, "Application-Layer Traffic Optimization (ALTO) Problem Statement," IETF RFC 5693, Oct., 2009.

[4] H.Xie, Y.R. Yang, A. Krishnamurthy, Y. Liu, A. Silberschatz, "P4P: Provider Portal for Applications," ACM SIGCOMM, pp.351-362, Aug., 2008.

[5] C. Wang, N. Wang, and M. Howarth, "A New Approach for Achieving Traffic-Exchange Localization in P2P-based Content Distribution," IEEE ICT'09, pp.59-64, May, 2009.

[6] Y.He, I. Lee, and L. Guan, "Distributed Rate Allocation in P2P Streaming," IEEE Multimedia Expo., pp.388-391, Jul., 2007. 
[7] R. Roverso, A. Naiem, M. Reda, M. El-Beltagy, and S. El-Ansary, "On the Feasibility of Centrally-Coordinated Peer-to-Peer Live Streaming,” IEEE CCNC pp.1061-1065, Jan., 2011.

[8] J.F. Buford, H. Yu, and E.K. Lua, P2P Networking and Applications, Morgan Kaufmann, MA 2009.

[9] S. Boyd, and L. Vandenberghe, Convex Optimization, Cambridge Univ Press, 2010.

[10] R. Nunez-Queija, and B. Prabhu, "Scaling Laws for File Dissemination in P2P Networks with Random Contacts," IEEE IWQoS, pp.75-79, Jun., 2008.

[11] J.-W. Ding, G.-W. Wu, and D.-J. Deng, "Optimal Rate Allocation and Admission Control Policy for P2P On-Demand Streaming Systems," IEEE IIH-MSP, pp.1232-1235, Sep., 2009.

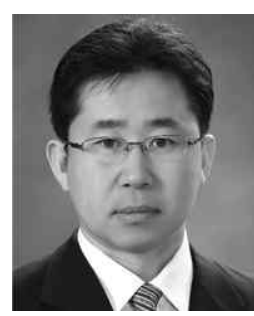

\section{박 재 성}

e-mail : jaesungpark@suwon.ac.kr 1995년 연세대학교 전자공학과(학사)

1997년 연세대학교 전자공학과(공학석사)

2001년 연세대학교 전기,전자공학과(공학 박사)

2001년 2002년 University of Minnesota (Research Faculty)

2002년 2005년 LG전자 선임연구원

2005년 현 재 수원대학교 정보보호학과 조교수 관심분야: 네트워크 성능 분석 및 프로토콜 개발 